https://doi.org/10.48009/1_iis_2005_87-93

\title{
CREATING VALUE IN ONLINE COLLABORATION IN ECOMMERCE
}

\author{
Dr. Steven A. Brown, Capella University, stevenbrown@drstevenbrown.com
}

\begin{abstract}
As ecommerce continues to grow, the need for effective collaborative learning environments will continue to grow. Collaborative communities can be leveraged for things such as distance education, business innovation, etc. but in order for these things to be leveraged to their maximum potential, value has to be created so that the costs participants give up, e.g., time, are acceptable given the potential benefits received. This paper begins to look at how value can be created in communities, and how it can foster a collaborative environment where innovation can occur.
\end{abstract}

Keywords: Collaboration, ecommerce, communities, value, laddering

\section{INTRODUCTION}

Effective communities are an important component in a collaborative learning environment, and help to improve the overall effectiveness of the channel. It is important, however, that value be created in this channel. Without value being created, participants will not use these communities. Collaboration can be defined as an effective communication process that uses several avenues to leverage and maximize this online interaction. By the use of available tools, such as discussion forums, email lists, and other specialized tools, effective communications can be leveraged for maximum efficiency, which may lead to innovation among its participants [1].

\section{Online Communities}

Typically, collaboration has centered on individuals and groups. These small meeting points have grown into very large focused communities, e.g., blogs, that target specialized areas of interests and distribution channels. Communities provide for the foundations for interorganizational collaboration. They bring together the participants that use the information communities provide to support the exchange process, i.e., the actual buying and selling. They encompass the forums, discussion groups, exchange of industry information, and iterative interactions for an innovative environment. Communities do not include the facilities to complete business transactions directly, but are needed as a catalyst to close these transactions.

Communities are being developed into e-learning areas, which provide a rich curriculum to a users portable device, e.g., desktops, PDAs, etc. By establishing this collection of resources, partners of this community, e.g., students, faculty, etc., can meet and discuss important issues in this collaborative community. Communities can be viewed both positively and negatively; for example, consumers can view communities from a pure informational resource that distinguishes products and services based on a metric, i.e., a rating scale. However, organizations view these communities as a dual-edge sword, one that encourages innovation, or a waste of organizational resources if individuals spend too much time in these communities. Communities can help 
research new ideas, enhance interactive dialogue, and allow feedback and a wealth of additional information to its participants.

\section{Creating Value}

In any collaboration effort, value needs to be offered. More importantly in an online environment since participants may not be geographically close, and in order to participate in this community, they must feel they are receiving some value in return for their participation. Many companies face problems delivering value over the Internet, since it is much more than simply doing business online; it is about the integration of a company's electronic commerce potential into the entire value chain [3].

Several researchers have attempted to define value. A review of the literature reveals some researchers believe that value is received in a means-end way, i.e., by the use of a product or service attributes, the consequences from using those attributes, and the goals of the individual participant [11]. Individuals, who judge value, do so in a way that will help them achieve their higher-level goals, and they place value on the use of these products and services that help them achieve their goals. Some models exist to help researchers determine how to uncover these goals in traditional markets [6]. Since conventional markets do not exist in e-commerce, value has to be delivered in its products and services, and how individuals judge what is value [7].

This research examines some of the ways value can be deliver over the Internet, and in electronic commerce. By identifying those attributes that lead to consumer's desired end goals, value can be created and the linkages identified from attribute to consequence to goal. Research does suggest that certain attributes associated with Web sites can lead to a more enhance experience and will lead to more customer loyalty [8]. Companies can offer value by using an effective Web-strategy that includes value-added services [10]. The issue then, is what are these valueadded services. Moreover, can Information Technology systems be a catalyst for a firm to reach its desired strategic vision [4].

\section{Research and Methodology}

Before establishing the value components, we need a starting point. Electronic commerce is too considerable in size to simply elaborate on all the available attributes that are associated with ecommence. Electronic commerce is better illustrated in distinct categories. Similar to an automobile, and its categories of engine, transmission, interior, fuel system, environment controls, etc., a categorization of electronic commerce components is needed so that companies can understand how value is delivered in each of these distinct categories associated with electronic commerce. Electronic commerce can be broken into several categories, e.g., communities, procurement, service, etc., this makes each category distinct and value components can better be identified. If we were to discuss an automobile interior, we could discuss climate control, upholstery, seat and neck supports, etc. In electronic commerce, and collaborative communities, we can focus on those aspects that are native to communities, e.g., email lists, portals, forums, etc. 
In Gutman's [6] means-end chain, motivation moves people to reach their end goal. This chain is a linkage that ties the attributes, consequents and goals together, which in turn make up a persons goal hierarchy. This hierarchy helps individuals break up a problem into smaller pieces and makes the problem more manageable [3].

Consumers learn to judge, which consequences are desirable and which ones are undesirable. These learned behaviors motivate people to choose those consequences that are desirable, and avoid from those that are not, and they apply value judgments to these consequences. Further, they place value on these consequences knowing from past history whether or not their goals will be reached [6].

A technique used to identify these value components is by the use of laddering. This process is a qualitative interview that leads a person up a level of abstraction and creates a linkage that ties in attributes, consequences, and goals, to finally, an individuals complete value system [5].

Gutman [6] explains that:

"Why" probes are used to prompt people to think about higher-level concepts; "how" probes encourage thinking about lower-order components of goal hierarchies. Laddering, then, can be considered to be an approach for eliciting a person's hierarchical set of goals with regard to a particular consumer decision [p.549].

In this research we use the laddering concept in the category of communities to uncover the linkages and identify how value is delivered in this medium. An example offered by Brown [1] of a laddering dialogue in the category communities, consisted of the following:

Researcher: When looking at the various electronic commerce categories, could you describe an attribute you find important in communities?

Respondent: Public and private Intranet portals.

Researcher: What you mean by public and private portals?

Respondent: For example, Intranet portals created for my suppliers or distributors, each having different access levels, and public portals for other parties.

Researcher: Why would that be important?

Respondent: Well, my distributors and suppliers appreciate the additional access, and learn more about my business. I can make information available to them on a need to know basis, and in real-time, hopefully increasing our collaboration and productivity.

Researcher: So during the normal course of business dealings, you can update and modify information that your distributors or suppliers can access, and even find a way to increase collaboration between the various parties. 
Respondent: Exactly.

Researcher: Why would allowing them to have this information benefit you?

Respondent: The more these parties have additional information about our business; the faster they can react to our needs. For example, market conditions change, the demand for our raw material might skyrocket, etc. We may not notice it right away, but they might, and may be in a better position to help us handle our chain.

Researcher: So by creating these different Intranet portals, we are creating a community, whereby we can share information with our distributors and suppliers, with the goal being that they can react to market conditions faster to help our company.

Respondent: Exactly.

In this interview, the respondent conveyed an attribute, consequence and goal for the category communities as follows:

Goal: $\quad$ Partners Act Quickly to Help

Consequence: Collaboration.

Attribute: Public and Private Intranet Portals.

This type of research helps to reveal these means-end linkages and uncovers the specific attributes that lead to certain consequences, and finally to individuals goals. This type of qualitative research is very helpful in uncovering these chains.

\section{Data Collection}

Initial data collection consisted of thirty in-depth interviews with individuals who specialized in Business-to-Business (B2B) electronic commerce and who could articulate important value B2B components in the category under investigation. The individuals who participated in these interviews covered a number of industries, e.g., automotive, retail, services, leisure, etc., that offered or engaged in some type of B2B transaction. Some were from firms with 100 or fewer employees; some were from companies with hundreds of employees, and some were from multinational corporations with thousands of employees. Because this research was about identifying those value components in $\mathrm{B} 2 \mathrm{~B}$ collaboration, it was important that the researcher identify those individuals who could articulate the important value components. The titles of these individual varied from Senior Marketing Executive, Vice President, Senior Manager, etc. However, they were all in the position to successfully conduct the interview with the researcher. After the interviews are completed, they are analyzed for categorical commonality. During each interview, the researcher simply writes down what was said. After the interviews, the researcher then examined each linkage for any commonalities.

It is important to categorize these interviews for common generalities by attribute, consequence, and goal, as Reynolds and Gutman [9] state: 
obviously, one wants to achieve broad enough categories of meaning to get replications of more than one respondent saying the one element leads to another. Yet, if the coding is too broad, too much meaning is lost. The key to producing consistency in this stage, as in all content analysis, is reliability checks across multiple coders Importantly, the goal at this level of the analysis is to focus on meanings central to the purpose of the study, remembering that it is the relationships between themselves. For example, "avoids the negatives of alcohol" in figure 1 is a summarization of several more detailed elements (namely, not too tired, not too drunk, don't say dumb things, and don't get numb). If all those separate elements were given separate codes it is likely that none of the relations between them and other elements would have very high frequencies [p.19].

Once the interviews are complete, the researcher creates a hierarchical value or consumer decision map (see Figure 1.0). The purpose of these interviews is to form categories of these linkages and help to produce a matrix to form a complete hierarchical map, in this case, communities in electronic commerce. This forms a map that is easy to read and understand, and illustrates the linkages from attribute to goal.

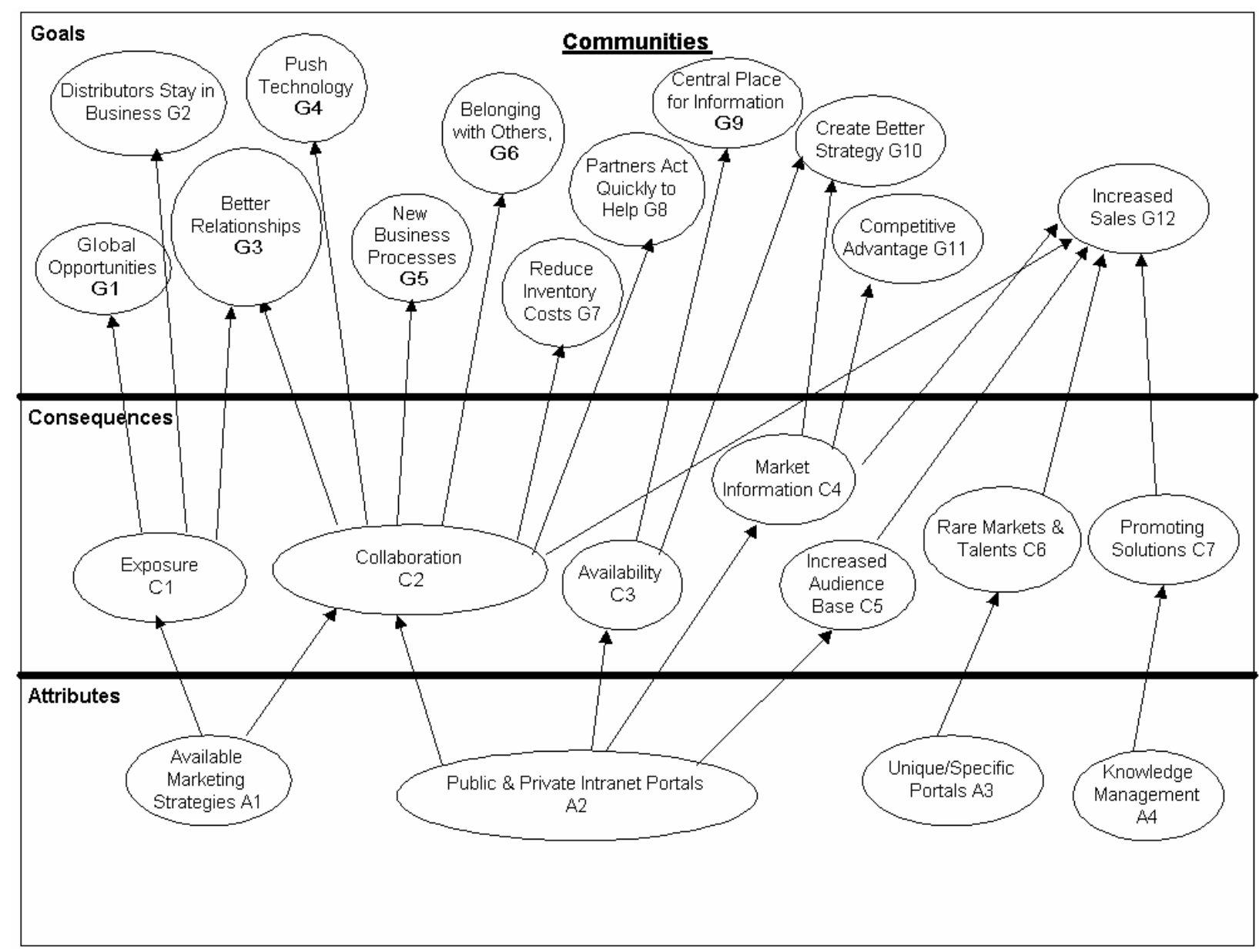

Figure 1.0: Consumer Decision Map for Communities Category 
Figure 1.0 lists the complete hieratical map that research has suggested for communities. Each attribute, consequence, and goal, is listed by number and identified. For example, the attribute Available Marketing Strategies, A1, is defined as the ability to share marketing strategies with others, and the goal, Distributors Stay in Business, G2, is defined as the ability for distributors to stay in business. Each attribute, consequence, and goal is identified in this way. This identification serves to capture the common meaning of all the interviews, and easily identifies the important value linkages.

\section{CONCLUSION}

Online collaboration is an important tool in ecommerce, and communities can help foster this environment and enhance this collaborative effort. However, in order to augment this channel, value must be created in the channel, and careful attention needs to be considered how this value is created and managed. For example, in Figure 1.0, it can be seen that attribute, Available Marketing Strategies, A1, leads to consequences, Exposure, C1 and Collaboration, C2, which leads to goals, Global Opportunities, G1, Distributors Stay in Business, G2, Better Relationships, G3, Push Technology, G4, New Business Processes, G5, Belonging with Others, G6, Reduce Inventory Costs, G7, Partners Act Quickly to Help, G8, and Increased Sales, G12.

It is important to recognize that while value maps illustrate the linkage from attribute to goal, it also identifies the steps that are needed, and the important consequences that must happen. For example, in the previous example, Collaboration, which may seem like an important goal to many, it is nevertheless a consequence. As can be seen in Figure 1.0, the goal is not collaboration, but the results from collaboration, e.g., Reduced Inventory Costs, G7, and Increased Sale, G12. This makes sense, since the actual act of collaboration isn't the end-goal, rather we use collaboration to achieve some end-goal, and has been correctly identified by these individuals as a consequence.

It is important therefore, that managers understand these linkages, how they are created. In this example, many higher-end goals, such as Better Relationships, G3, and Increased Sales, G12, are dependent on effective collaboration. If Collaboration, C2, which was based upon Available Marketing Strategies, A1, and Public \& Private Intranet Portals, A2 (and A1 and A2 were not managed correctly, collaboration will not occur, and these higher-end goals will not be reached. The value map shows the necessary components that must be appropriately managed, so that positive consequences will occur, and end-goals are reached.

It is also important to note the importance of Information Systems (IS) as it pertains to ecommerce. Examining some of the specific attributes in this research, Public \& Private Intranet Portals, A2, and Unique/Specific Portals, A3. It is critical to understand that it is by the successful implementation of IS systems and technologies that organizations can manage these attributes to reach their desired goals. Chief Information Officers and Chief Technology Officers should understand and appreciate the importance of IS systems, and the integration to successfully reach a firms strategic vision. Therefore, it is vital that both the business and the Information Technology department share the similar strategies. 


\section{REFERENCES}

1. Brown, S. A. (2003). The Creation of Value in Electronic Commerce, an Empirical Study. Unpublished doctoral dissertation, Nova Southeastern University, FL.

2. Bettman, J. R. (1979). An Information Processing Theory of Consumer Choice. Reading, MA: Addison-Wesley

3. Cavusgil, S. T. (2002). Extending the Reach of e-business. Marketing Management, 11(2), 24-29.

4. Frenzel, C.E., \& Frenzel, F.C. (2004). Management of Information Technology. Boston: . Thomson, Course Technology.

5. Gengler, C.E., Mulvey, M.S., \& Oglethorpe, J.E. (1999). A Means-End Analysis of Mothers' Infant Feeding Choices. Journal of Public Policy \& Marketing, 18(2), 172-188.

6. Gutman, J. (1982) A Means-End Chain Model Based on Consumer Categorization Processes. Journal of Marketing, 46(2), 60-72.

7. Kenny, R. L. (1999). The Value of Internet Commerce to the Customer. Management Science, 45(4), 533-542.

8. Reichheld, F., \& Schefter, P. (2000). E-loyalty. Harvard Business Review, 78(4), 105-113.

9. Reynolds, T.J., \& Gutman, J. (1988). Laddering Theory, Method, Analysis and Interpretation. Journal of Marketing, 28(1), 11-31.

10. Saeed, K., Hwang, Y., \& Grover, V. (2002). Investigating the impact of web site value and advertising on firm performance in electronic commerce. International Journal of Electronic Commerce, 7, 119-141.

11. Woodruff, R.B. (1997). Customer value: The next source for competitive advantage. Academy of Marketing Science, 25(2), 139-153. 